\title{
What if students propose their own examinations? An introductory experiment
}

\author{
Rojo, Marta ${ }^{\mathrm{a}}$; Preciado, Mónica ${ }^{\mathrm{a}}$; Gonzalo-Orden, Hernán ${ }^{\mathrm{a}}$; Moreno, Ignacio ${ }^{\mathrm{a}}$; \\ Casado, Silvia ${ }^{b}$ and Cárdenas, David ${ }^{a}$ \\ ${ }^{\mathrm{a}}$ Department of Civil Engineering, University of Burgos, Spain, ${ }^{\mathrm{b}}$ Department of Applied \\ Economics, University of Burgos, Spain.
}

\begin{abstract}
This paper presents a proposal experimented in the University of Burgos, where students of different degrees, at a Bachelor or Master level, had to prepare solved questions or exercises, in order to introduce some of them into the exams. There were considered three types of experiment: test, short questions and exercises. Students submitted they own proposals into forum, where the teacher corrected them and randomly selected some of them, which configured the half of the official exam. The obtained results were very positive: students had a very good perception of the experiment, learnt more and passed the subject easily. Also, the average grading were higher that the corresponding with the classical system, existing a slight correlation between this increase and their point of view about the chance to learn. The satisfaction and the marks of the students are higher, while having a better knowledge of the topics included. Also, students have the feeling that the teachers are more considerate and thoughtful with them, so this type of experiments should be continued.
\end{abstract}

Keywords: Grading; Students participation; Questioning. 


\section{Introduction}

Students, in general, tend to complain about the difficulty of tests, questions or exercises suggested by their teacher on exams. In some cases, it is the wording of the question that causes the problems, because the students do not understand what the teachers are asking them. All these circumstances are considered one of the causes of their low rating. Therefore, the authors have tried to change this situation, allowing students to prepare part of the exam, in a university setting.

We do have to be concerned that the old ways of teaching can be changed. Our students are different and need different strategies to connect them with the topics included in class (Biggs \& Tang, 2007; Ramsden, 1992). So we have to adapt our techniques in order to find ways to encourage and involve them in the learning process.

When analyzing the existing literature, Rosenshine et al. (1996) and Cano García et al. (2014) developed some experiments in which students were taught to generate questions about ways to improve their understanding. Hardy et al. (2014) introduced an online tool to facilitate learning, where students sent multiple-choice questions, with very good results. In fact, question-generation has been considered as a technique of training in metacognitive knowledge by different authors (Cano García et al., 2014; Wright, 2001; Chin \& Brown, 2002).

Ryan \& Deci (2000) formulated their theory of self-determination, which describes the effects of external events on motivation. If these events promote the belief that the person controls the results and encourages a sense of competition, the intrinsic motivation will increase. If these events favor the perception of incompetence and lack of control, the intrinsic motivation is weaken. Nicole and Macfarlane-Dick (2006) focused on the same idea, noting that research on formative assessment and feedback can help students take control of their own learning, becoming self-regulating learners.

Hence, in this paper we are looking for a tool that will allow students to become more involved in the teaching process, improving their motivation and their effort to achieve a deep learning in our subjects. In this case, we allow them to prepare part of the exam, so that, in some way, control the learning and qualification process.

The paper will be divided into four sections. The first section presents a brief introduction to the topic. Sections two and three describe the followed methodology and its practical application to a case study at the University of Burgos (Spain); the discussion and the analysis of the results are also shown. Finally, the main conclusions are presented in section four. 


\section{Methodology}

This paper presents an experiment developed at the University of Burgos (Spain), where students had to propose test or short questions and exercises, on certain subjects, that would be introduced in their exams. All subjects were included in Engineering or Business Administration and Management Degrees, at a Bachelor of Master level. The complete list of subjects in which the experiment was developed is presented in Table 1 below.

Table 1. Subjects involved in the experiment.

\begin{tabular}{cccc}
\hline Course & Subject & Year & No. students \\
\hline $\begin{array}{c}\text { Bachelor's Degree in Business } \\
\text { Administration and Management }\end{array}$ & Analysis of Financial Operations & First & 91 \\
Bachelor's Degree in Civil & Transports & Third & 28 \\
Engineering & Urban and Intercity Traffic & Third & 3 \\
Bachelor's Degree in Mechanical & Materials Engineering & Third & 46 \\
Engineering & Computer Equipment & Fourth & 14 \\
Bachelor's Degree in Computer & Maintenance & & \\
Science Engineering & Transport Systems & Second & 36 \\
Master's Degree in Civil & Traffic Engineering & Second & 10 \\
Engineering & Highway Management Systems & Second & 20 \\
& and Road Safety & & \\
\hline
\end{tabular}

Source: in-home.

In each of these subjects, students had to prepare test questions, brief questions or exercises for the application of knowledge learned in class. Depending on the nature of the subject, one or more type of question / exercise was developed, with its corresponding response. Part of the subject's qualification was related to the quality of these questions: assessing their accuracy, correctness of the answer and coverage of the whole topic.

In order to allow all students to know the questions of their colleagues, several forums were opened, and each group of students had to present their proposal there. Repeated questions or exercises were forbidden, and students had to read first the proposals already submitted, so that the whole topic was covered. These elements were corrected by the teacher, who published the correct answer (if necessary) in the same forum.

Half of the exam of the related topics was done through questions / exercises prepared by the students themselves, and the rest was prepared by the teachers. In this way, we can see 
the differences in the qualification between the part developed by themselves and the "classic" system.

Finally, after the exams, students were asked to respond to a survey of their experience with this type of qualification system. With this survey and their academic results, we can assess whether the new system is appropriate to these subjects or not.

\section{Results}

In this chapter, we analyze the results of the experiment. In the first part, the students' survey will be evaluated to know their degree of satisfaction with the new system. In a second part, we will compare the academic results (qualification) in both parts: the questions and exercises proposed by the students in the forums and those developed by their teacher.

\subsection{Survey Results}

As we have described previously, after the exam the students were asked to response an anonym interview, were they can express their degree of satisfaction with this system, and their personal opinion. In overall, 231 surveys were collected, which supposes a response index of the $93 \%$ of the students.

Among the different questions, included in this survey, we can note the next five ones:

- How have you studied with the new grading system?

- Do you think that you have learnt more with the new system?

- In which stage have you learnt more?

- Is passing the subject easier with the new system?

- Can you globally value the new grading system?

About the first question, we can note that most of students opted to study the whole material of the subject, having a look afterwards to the questions submitted to the forums. This issue is crucial for the remaining data, since the point of view of the students that only see the questions and exercises uploaded to the forum is different than the rest of their classmates. Figure 1 presents the results of this topic though the interviewees.

Concerning the second question, the results show that the $67 \%$ of students think that they have learnt more with the new system. However, those who only studied the uploaded questions/exercises had a lower value in this question than the rest (3.64 in comparison with around 4), so they had not the same degree of "exploitation" of the system. The results of the survey are presented in Figure 2. 
If we analyze when they have learnt more, the results are different again depending on their way of studying. Those who only studied the submitted questions note that the process of preparing these questions and exercises was the time when they learnt more. On the other hand, those who studied the complete material appreciate that have learnt in a similar way in both processes. In Figure 3 we can see the numerical results.

In Figure 4 we present the results concerning the ease to pass. In general terms, $54 \%$ of students perceive that it is easier with the new system rather than the classical one. However, if we analyze the surveys per type of question, the averages rates of this issue are: 3.41 for test questions, 3.26 for short questions and 3.23 for exercises. Thus, the feeling of "safety" in the students is higher in the test experiments, where they have a certain degree of closed questions for the exams.

Finally, we asked them about their degree of satisfaction with the new grading system. The results are shown in Figure 5, where we can see that students are very happy with it, with an average value of 4.02 .

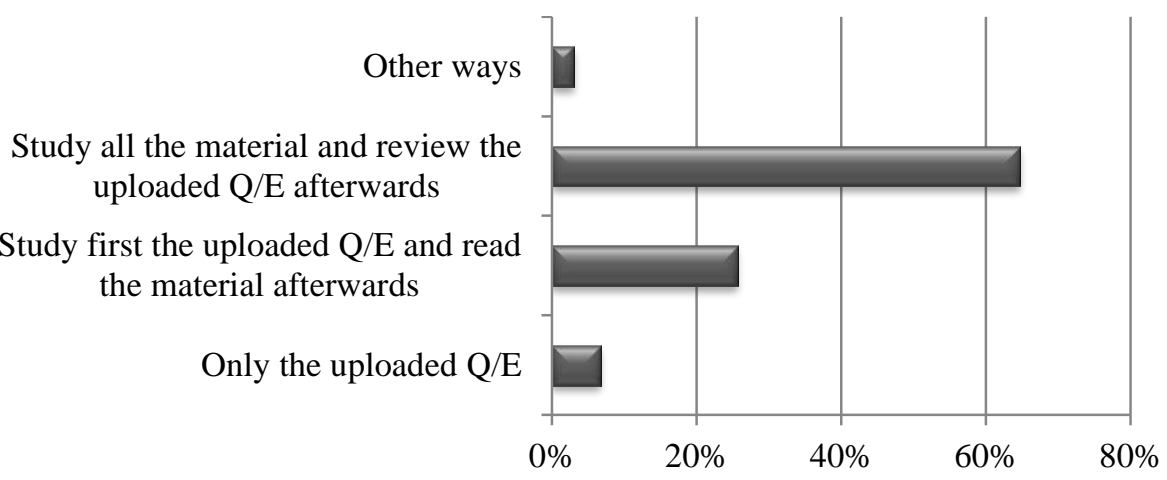

Figure 1. How students have prepared the exams. Source:in-home.

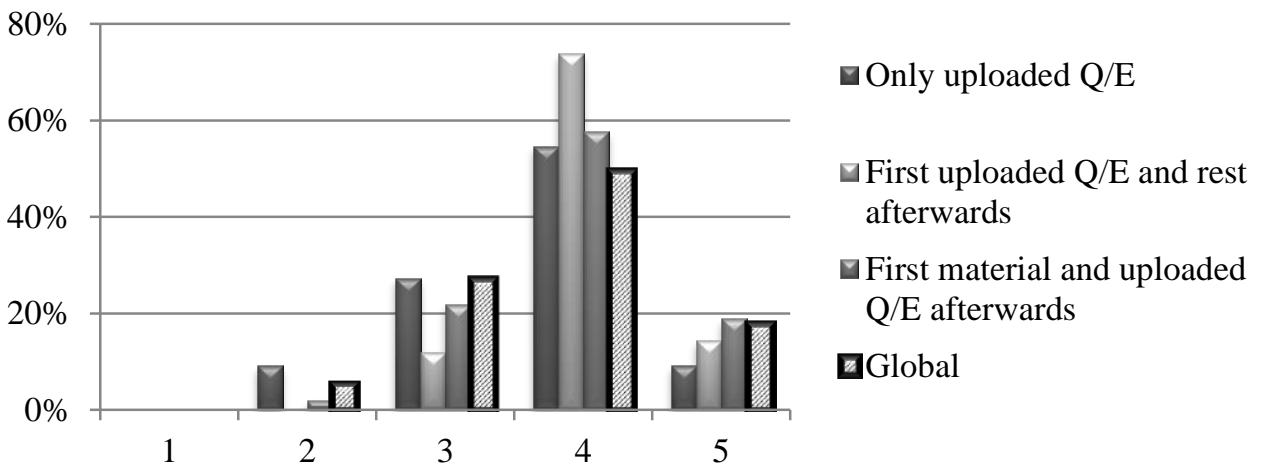

Figure 2. Students have learnt more with the new system (1 - totally disagree; 5 - totally agree), depending on the way that they prepared the exams. Source:in-home. 


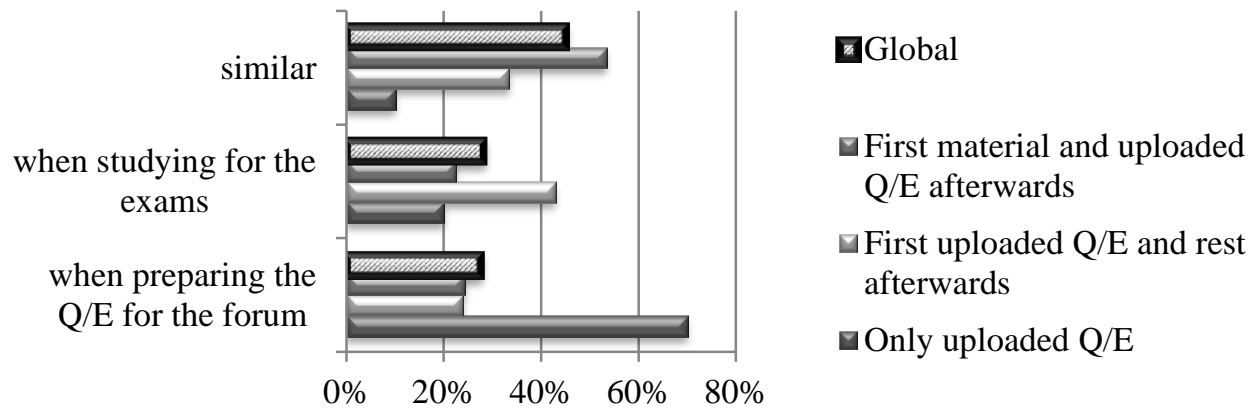

Figure 3. When did students learn more, depending on the way that they prepared the exams. Source:in-home.

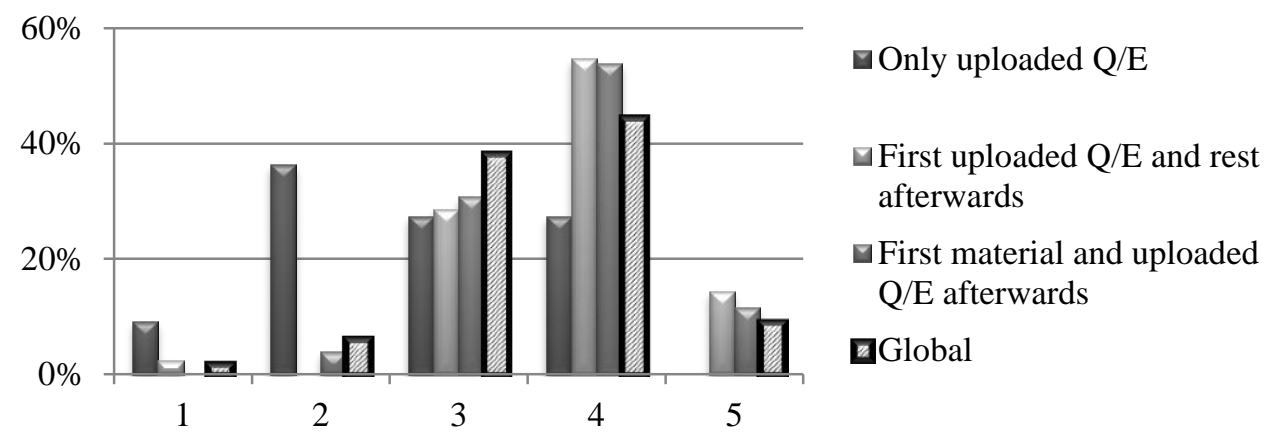

Figure 4. Passing is easier with the new system (1 - very much harder; 5 - very much easier), depending on the way that the students prepared the exams. Source:in-home.

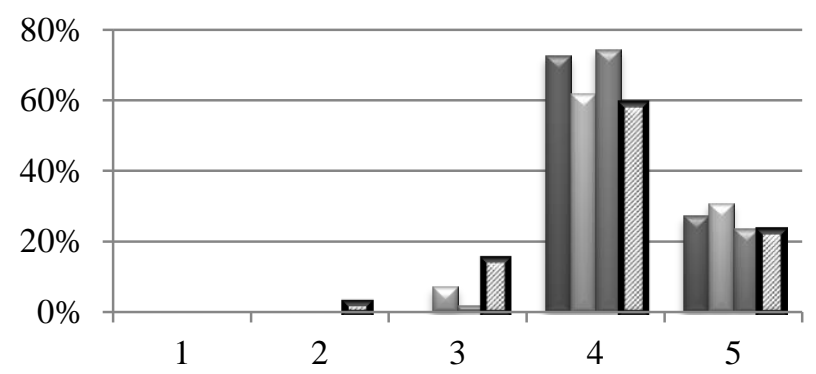

๑Only uploaded Q/E

$\square$ First uploaded $\mathrm{Q} / \mathrm{E}$ and rest afterwards

$\square$ First material and uploaded Q/E afterwards

Figure 5. Overall satisfaction with the new system (1 - very bad; 5 -very good), depending on the way that the students prepared the exams. Source:in-home.

With these results, we can conclude that, even when all the students have declared that they "like" the new system and have learnt more this way, the degree of "exploitation" of it is not same for all of them. Some of them have really used to have a continuous learning during the term, while other only considered it an easier way to pass the subject. In the next section, we will assess if the valuation corresponds with a real improvement in the students' grading. 


\subsection{Grading Results}

In the survey, students have stated that they prefer the new system and that they have learnt more and passed easier with it, rather than the classic one, where teachers decided which questions or problems would be introduced in the exams. In this section, we will compare their qualifications between the half of the exam proposed by themselves and the part prepared by the teachers.

In the first part, we can notice the real improvement in the grading with the new system, if we compare it with the classic one. These results are shown in Table 2, for each considered subject. The presented grading was obtained in the same exams, but differentiating the questions or exercises prepared by the students (new system) and teachers (classical one).

Table 2. Subjects average grading (from 0 to 10).

\begin{tabular}{|c|c|c|c|c|c|c|c|c|c|c|}
\hline \multicolumn{2}{|c|}{ Subject } & 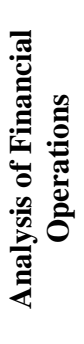 & 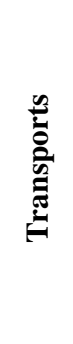 & 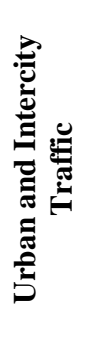 & 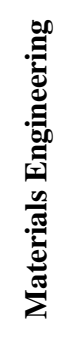 & 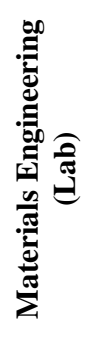 & 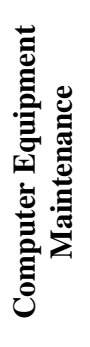 & 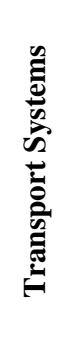 & 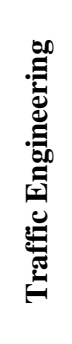 & 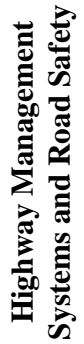 \\
\hline \multirow{3}{*}{$\begin{array}{c}\text { Test } \\
\text { grading } \\
(0-10)\end{array}$} & New system & & & & 8.0 & 7.5 & 8.4 & & & \\
\hline & Classic system & & & & 4.3 & 7 & 7.8 & & & \\
\hline & Improvement & & & & $86 \%$ & $7 \%$ & $8 \%$ & & & \\
\hline \multirow{3}{*}{$\begin{array}{c}\text { Short } \\
\text { questions } \\
\text { grading } \\
(0-10)\end{array}$} & New system & & 6.0 & 7.2 & 6.4 & & & 6.3 & 8.4 & 8.5 \\
\hline & Classic system & & 5.2 & 5.5 & 5.8 & & & 5.5 & 6.5 & 7.3 \\
\hline & Improvement & & $15 \%$ & $31 \%$ & $10 \%$ & & & $15 \%$ & $29 \%$ & $16 \%$ \\
\hline \multirow{3}{*}{$\begin{array}{c}\text { Exercises } \\
\text { grading } \\
(0-10)\end{array}$} & New system & 5.2 & 7.4 & 8.6 & & & & & 9.3 & \\
\hline & Classic system & 3.8 & 5.2 & 4.9 & & & & & 8.2 & \\
\hline & Improvement & $37 \%$ & $42 \%$ & $76 \%$ & & & & & $13 \%$ & \\
\hline
\end{tabular}

Source: in-home.

Analyzing these data, we can see than there is an improvement in the qualification of the students in all type of exams, whereas the type of short questions is slightly smaller than the rest of experiments. The greater increase was obtained in the problems (exercises) exam. 


\section{Conclusions}

In this paper, we present an introductory experiment on how to include students in the process of preparing exams, at university level. Asking the students a comprehensive survey, we have noticed that they were satisfied with the experiment, and they declared that they have learnt more by this method, because they had to read the whole topic to propose a good question. In addition, their scores have improved, in a different amount depending on the type of exam. However, we cannot forget that there are students who only read the questions and exercises from the forums, so they do not have a complete experience. This is a fact that the authors will try to change in future approaches.

Finally, we can conclude that this new grading system has resulted in a Win-Win strategy, as both students and the teacher achieve their goals: students are happier and mark higher, while having a better knowledge of the topics included. Perhaps this type of experiences, where students have a higher leadership of the whole process, is the future of the university academic teaching.

\section{References}

Biggs, J. \& Tang, C. (2007). Teaching for Quality Learning at University. New York: McGraw Hill.

Cano García, F., García, Á., Berbén, A. B. G., Pichardo, M. C. \& Justicia, F. (2014). The effects of question-generation training on metacognitive knowledge, self regulation and learning approaches in Science. Psicothema, 26(3), 385-390.

Chin, C. \& Brown, D. E. (2002). Student-generated questions: A meaningful aspect of learning in science. International Journal of Science Education, 24(5), 521-549.

Hardy, J., Bates, S. P., Casey M. M., Galloway K. W., Galloway, R. K., Kay, A. E. Kirsop, P. \& McQueen H. A. (2014). Student-generated content: Enhancing learning through sharing multiple-choice questions. International Journal of Science Education, 36(13), 2180-2194.

Nicol, D. J. \& Macfarlane-Dick, D. (2006). Formative assessment and self-regulated learning: a model and seven principles of good feedback practice. Studies in Higher Education, 31(2), 199-218.

Ramsden, P. (1992). Learning to teach in higher education. Studies in Higher Education, $18(1), 105-111$.

Rosenshine, B., Meister, C. \& Chapman, S. (1996). Teaching students to generate questions: A review of the intervention studies. Review of Educational Research, 66(2), 181-221.

Ryan, R. M. \& Deci, E. L. (2000). Self-determination theory and the facilitation of intrinsic motivation, social development, and well-being. American Psychologist, 55(1), 68-78.

Wright, J. (2001). The Savvy Teacher's Guide: Reading Interventions That Work. www.interventioncentral.org 